\title{
DE ORIENTE A OCCIDENTE. UNA LETRA DE BRONCE DE CINGULUM MILITARE HALLADA EN EL AGER TARRACONENSIS*
}

\author{
FROM EAST TO WEST. A CINGULUM MILITARE BRONZE LETTER FOUND \\ IN THE AGER TARRACONENSIS
}

POR

\author{
JoAQuín RuIZ de Arbulo BAyona** y JoRdi LÓPEZ VILAR ${ }^{* * *}$
}

\section{RESUMEN - ABstract}

Estudio de una letra de bronce hallada en las proximidades de Tarraco. Formó parte de la decoración de un cinturón militar con una inscripción que mostraría probablemente el nombre de su poseedor acompañado de la expresión utere felix, propio de la indumentaria militar característica del limes danubiano en los siglos II y III d. C. Se incluyen referencias a soldados orientales testimoniados epigráficamente en la ciudad.

Study of a bronze letter found in the vicinity of Tarraco. It was part of the ornaments of a military belt typical of the military clothing of the $2^{\text {nd }}-3^{\text {rd }}$ centuries in Danubian limes, with an inscription showing the name of its owner, probably accompanied by the expression utere felix. References to inscriptions from Tarraco referring to eastern soldiers are also included.

\section{Palabras Clave - Keywords}

Utere felix, cingulum militare; ejército romano; Tarraco.

Utere felix; cingulum militare; Roman army; Tarraco.

\section{CÓMO CITAR ESTE ARTículo / CitATION}

Ruiz de Arbulo Bayona, J. y López Vilar, J. (2021): «De Oriente a Occidente. Una letra de bronce de cingulum militare hallada en el ager Tarraconensis». Gladius, 41: 121-128. https://doi.org/10.3989/gladius.2021.06

\footnotetext{
* Este artículo se enmarca en el proyecto cuadrienal financiado de la Generalitat de Catalunya CLT009/18/00031: "Guerra i conflicte al nord-est de la Península Ibèrica en època romanorepublicana (segles III-I aC)" (años 2018-2021). Agradecemos a los profs. Juan Manuel Abascal y Diana Gorostidi la lectura del texto y sus siempre oportunas observaciones que nos han sido de gran utilidad. También la tarea de los evaluadores de Gladius que nos ha permitido corregir un error.

** Universitat Rovira i Virgili, Institut Català d'Arqueologia Clàssica, Tarragona, joaquin.ruizdearbulo@urv.cat / jruizdearbulo@icac.cat / ORCID iD: https://orcid.org/0000-0001-9356-3790

${ }^{* * *}$ Institut Català d'Arqueologia Clàssica, Tarragona, jlopez@icac.cat / ORCID iD: https://orcid.org/0000-0002-6541-9705
} 


\section{PRESENTACIÓN DEL HALLAZGO}

Presentamos una pieza singular procedente de una colección particular, encontrada de forma casual hace años en un lugar no precisado de la comarca del Alt Camp a unos $20 \mathrm{~km}$ al norte de Tarragona $^{1}$. Se trata de una pequeña letra $S$ realizada en bronce con unas dimensiones de $36,5 \mathrm{~mm}$ de altura; $20 \mathrm{~mm}$ de anchura; y un grosor de 2,5-3 mm. Está dotada en su parte trasera de dos espigas de sujeción de $6 \times 6 \times 5 \mathrm{~mm}$ de profundidad (Fig. 1).

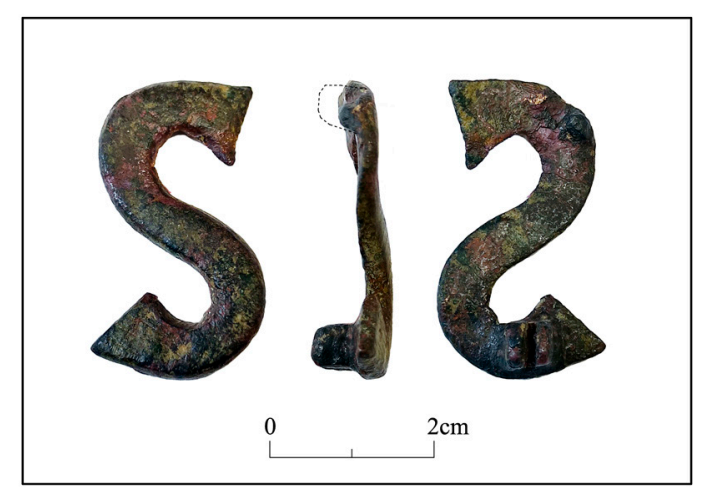

Figura 1. Letra S hallada cerca de Tarraco (foto: ICAC/ I. Matias).

Como veremos a continuación se trata con seguridad de un elemento de vestuario militar romano. Concretamente pertenece a la decoración con una frase propiciatoria de un cinturón de cuero característico de los siglos II y III d. C. Aunque se trate de un hallazgo mínimo y por desgracia descontextualizado, su presencia en Tarragona y en Hispania representa una novedad importante ya que estos cinturones fueron propios de las legiones estacionadas en el limes danubiano y hasta el momento solo conocíamos en Occidente un ejemplar completo procedente de Lyon.

\section{LOS CINGULA MILITARIA CON EXCLAMACIÓN UTERE FELIX. HISTORIOGRAFÍA, DISPERSIÓN Y CRONOLOGÍA}

En 1950 las obras de un parking en la ciudad de Lyon, calle Fantasques núm. 10, sobre la al-

${ }^{1}$ El hallazgo ha sido comunicado por el Sr. Francesc Llagostera, quien nos ha cedido la letra para su estudio y depósito en el Museu Nacional Arqueològic de Tarragona. tiplanicie de la Croix-Rousse, permitieron documentar restos arrasados de muros romanos y la parte inferior de un esqueleto asociado con armamento militar. Se trataba de una espada larga (spatha), contera, falera, placa terminal de la decoración metálica de un tahalí, una fíbula acodada y una serie de nueve pequeñas letras de bronce de aproximadamente $2,5 \mathrm{~cm}$ de altura: E, E, E (con arandela inferior), F, I, L, R, UT, X. Dos de ellas - UT y X - quedaban ligadas respectivamente a un engarce y una hebilla demostrando así la función de todo el conjunto de letras como la decoración escrita de un cinturón de cuero al que irían cosidas las letras. También apareció un pequeño lote de doce monedas de bronce escalonadas desde Marco Antonio (33-31 a. C.) hasta Septimio Severo (194 d. C.) probablemente guardadas en un pequeño marsupium o bolsa monetaria. El conjunto de piezas quedó depositado en el entonces Museo Galorromano de Fourvière (Wuilleumier, 1950; Bullinger, 1972; restitución de la panoplia en Bishop y Coulston, 2006: fig. 101) (Fig. 2).

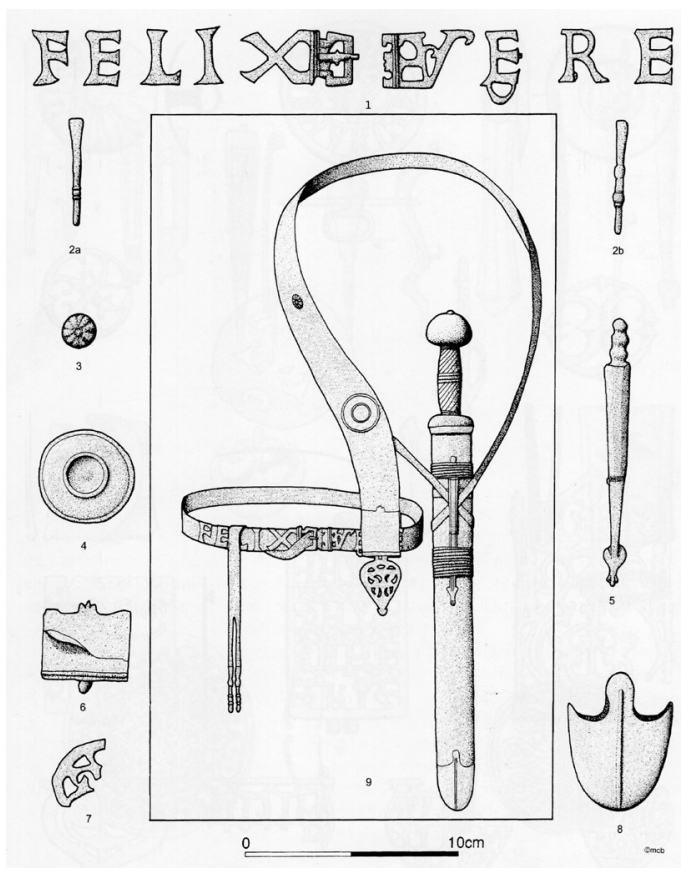

Figura 2. Restitución de la panoplia de la tumba de Lyon (de Bishop y Coulston, 2006: fig. 101).

La datación del conjunto monetal permitió proponer que se tratara de los restos de un soldado fallecido en la batalla de Lugdunum del 197 d. C. que puso fin a la rebelión de Albino - que tam- 
bién encontró en ella la muerte- por parte de las tropas de Septimio Severo (Wuilleumier, 1950). El hallazgo ha sido ahora catalogado y estudiado de nuevo por Lucas Guillaud incluyéndolo en su magnífico y muy completo volumen sobre el armamento romano aparecido en Lugdunum (Guillaud, 2019: 120, 243-246, catálogo núm. 200 a-i, lám 29).

En un primer estudio de estas letras, P. Wuilleumier (1950) habría reconstruido de forma errónea la inscripción reconociendo la fórmula (UT)ERE FELIX-(hebilla) pero separando como una nueva palabra la ligatura LAE unida al engarce (lae[te]/[a]lae?). Esta interpretación [Ut] ere felix lae[te] pasaría a los repertorios epigráficos (ILTG 569 y AE, 1952, 75) condicionando otros estudios posteriores como el de H. Bullinger (1972) que reconocería no obstante la expresión Utere Felix incisa sobre hebillas de cinturones bajo-imperiales recogiendo igualmente otras letras aisladas de bronce muy semejantes en los museos de Viena y Budapest.

Fue mérito de G. Ulbert (1974) la identificación correcta de esta inscripción lugdunense entendiendo simplemente que la supuesta ligatura LAE-(engarce) debía en realidad girarse 180 grados de acuerdo con su unión a la hebilla contraria para convertirse en la ligatura UT. Se completaba así correctamente la secuencia de la inscripción del cinturón como (engarce)-UTERE FELIX(hebilla). Una de las letras E está provista además de un pequeño aro inferior para pasar un cordel ${ }^{2}$. G. Ulbert había conocido ya el hallazgo en 1962 de un cinturón con inscripción del todo similar aparecido en un contexto estratigráfico en el gran santuario termal de Aquae Iasae, en Panonia, actual Varaždinske Toplice (Croacia) con la secuencia (engarce)-UTE[re] FELIX-(hebilla), conservando 10 letras sobre un total de 12 (Ulbert, 1974: 211-215; ver ahora estudio específico en Galić

\footnotetext{
${ }^{2}$ La presentación actual en el Museo de Fourvière de este cinturón que muestran las redes sociales mantiene todavía la primera e incorrecta propuesta de Wuilleumier por razones que se nos escapan. También la base de datos Clauss/Slaby que consultamos el día 04/08/2020 al copiar directamente la voz en los repertorios epigráficos ILTG y AE seguía manteniendo para el cinturón de Lyon la primera restitución errónea [Ut]ere felix lae[te] que debería haber sido corregida con total seguridad como Utere felix desde la publicación de G. Ulbert en 1974. Al recibir nuestro aviso con las referencias bibliográficas oportunas, el Prof. Dr. Manfred Clauss ha tenido la amabilidad de actualizar efectivamente el texto en la ficha EDCS-13303417 con fecha 16/08/2020.
}

y Radman-Livaja, 2006 y mención en catálogo Radman-Livaja, 2010: 254, núm. 5) (Fig. 3).

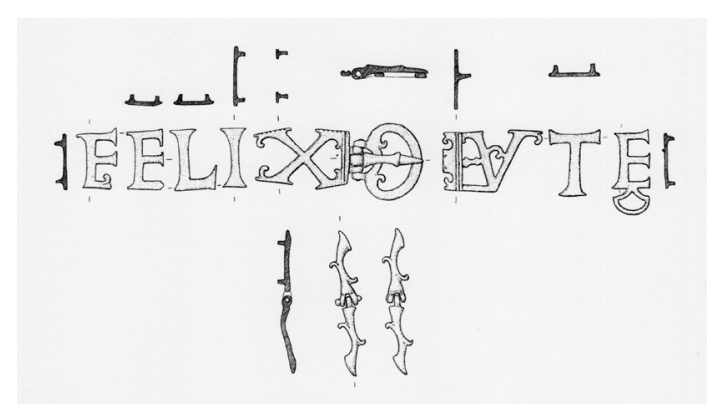

Figura 3. Cinturón de Aquae Iasae (de Galić y Radman-Livaja, 2006: fig. 2).

La restitución es del todo segura ya que desde el año 1979 se conoce un segundo ejemplar completo de cinturón decorado con idéntica inscripción (engarce)-UTERE FELIX-(hebilla), pero en este caso con letras de plata (Ovčarov, 1979: 3346). Se trata de un hallazgo funerario efectuado en Ljublen (Bulgaria), en el interior de un túmulo con doble inhumación asociada a un ajuar de instrumentos quirúrgicos correspondiente probablemente a un médico militar, con una datación numismática de 9 monedas acuñadas entre los años 218 y 225 d. C. (Ovčarov, 1979; Petculescu, 1995: 393; Redžić, 2009: 156). Otra variante de esta panoplia en su versión más lujosa se reconoce en un nuevo conjunto de seis letras de plata (una de ellas unida a una hebilla) publicadas por Stefanie Hoss (2006: 237-239, fig. 1). Son de origen desconocido ya que proceden del mercado de antigüedades y actualmente están en una colección particular, pero con seguridad pertenecen a otro cinturón esta vez con advocación escrita en letras capitales griegas: (hebilla)-MNHMQN, "Recuerda..." (Hoss, 2006: 237-239, fig. 1) (Fig. 4). La utilización de elementos y adornos de plata en el equipo militar sería un privilegio según Hoss (2017: 89) de los centuriones.

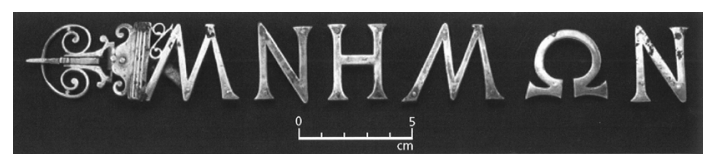

Figura 4. Cinturón con letras griegas de plata MNHM $\Omega N$ (de Hoss, 2006).

La correcta restitución de las inscripciones de los cinturones del tipo Lyon / Ljublen resultó 
esencial para la interpretación de otros hallazgos similares muy frecuentes, por ejemplo, en la $\mathrm{Da}-$ cia romana (Petculescu, 1991 y 1995). Al igual que en nuestro caso tarraconense, los hallazgos corresponden normalmente tan solo a una o algunas de estas pequeñas letras de bronce provistas en su parte trasera de chatones y pequeños agujeros para su cosido a láminas de cuero incluyendo entre ellas las letras inicial y terminal de la inscripción unidas respectivamente a engarce y hebilla. Las síntesis recientes de S. Hoss (2006) y S. Redžić (2009, con mapa de distribución en fig. 1) han completado los estudios de dispersión inventariando en 25 localidades diferentes las 90 letras de este tipo de cinturones hasta ahora conocidas y que se extienden a lo largo de las diferentes provincias del limes danubiano en las actuales Alemania, Croacia, Austria, Rumanía, Eslovenia, Eslovaquia, Hungría y Siria (Fig. 5).

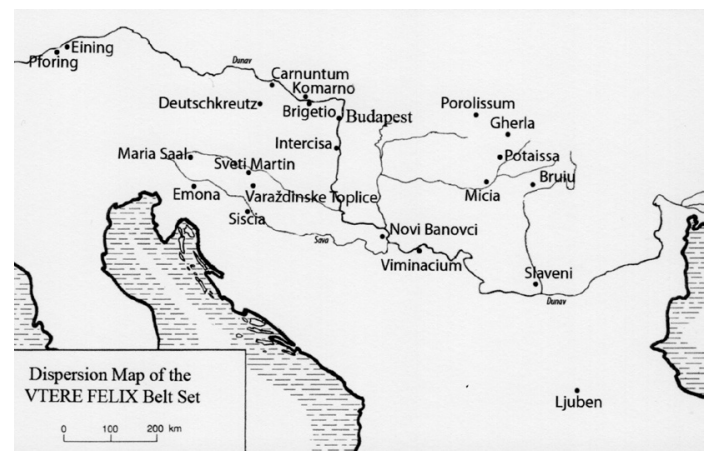

Figura 5. Mapa de dispersión cinturones del tipo Utere felix (de Redžić, 2009).

La práctica totalidad de las letras y con ellas de los cinturones UTERE FELIX hasta ahora documentados proceden de contextos militares, ya sea en áreas campamentales o necrópolis, con dataciones numismáticas que se inician con Marco Aurelio y Cómodo y se prolongan hasta bien entrado el siglo III d. C. (Petculescu, 1991; Hoss, 2006: 243; Redžić, 2009: 158-159). Destacan, además de los tres cinturones completos ya citados en Lyon, Ljuben y Varaždinske Toplice, las 26 letras halladas en diferentes contextos de $\mathrm{Vi}$ minacium, en Mesia, y las 12 letras halladas en Carnuntum, Panonia (Redžić, 2009). Las características de estos cingula son siempre idénticas: los textos conservan los términos UTERE y FELIX que pueden ser ordenados a la inversa FELIX UTERE según coloquemos el engarce y la hebilla en el centro de la inscripción cuando el cinturón era anudado en la cintura o bien en los dos extremos al quedar desplegado. Solo una de las letras E de toda la inscripción tiene como elemento singular en su parte inferior una pequeña arandela para que pueda pasarse por la misma el cordel de un pequeño marsupium monetario como en el caso de Lyon, anudar un cordel con el extremo del tahalí de la espada o quizás un adorno equivalente a las decoraciones metálicas del extremo del cinturón, pequeñas lúnulas cuyo tintineo característico advertía del paso del soldado convirtiéndose en símbolo de la milicia (Hoss, 2006: 38). Fue esta la sustitución del característico mandil de tiras de cuero cubiertas de discos metálicos rematados con pequeños colgantes que pendían de la parte delantera del cinturón cubriendo los genitales en la armadura legionaria alto imperial ${ }^{3}$.

Es cierto que el carácter propiciatorio de la inscripción UTERE FELIX "úsalo felizmente, úsalo con suerte" no tenía por qué ser exclusiva de la vida militar. La fórmula está compuesta por el imperativo presente de utor y por el adjetivo atributo felix como predicado con funciones de adverbio. Bullinger (1972: 277) citaría como paralelo una aclamación del Senado a Probo (Hist. Aug., XI, 7 y 9): felix imperes. Se conocen numerosos ejemplos en Hispania recopilados por J. M. Abascal (2003) de esta frase propiciatoria inscrita sobre todo tipo de soportes: desde chatones de anillos, hebillas, fíbulas y lucernas, hasta mosaicos o incluso uno de los ladrillos de la villa astur de Veranes (Gijón) sobre el que se escribió con carboncillo utere felix domum tuam (Fernández et alii, 2010). En todos los casos se expresa una advocación de felicidad, fortuna y suerte para los poseedores y como tal se transmitiría también al mundo paleocristiano con un total de hasta 272 referencias recopiladas en la base de datos epigráfica de Claus-Slaby.

Aun así, parece evidente el carácter muy homogéneo de estas letras de bronce cosidas al cuero de los cinturones cuya dispersión nos permiten considerarlos cingula militaria, elementos de un vestuario militar que debería ser propio tan solo de las legiones danubianas ya que excepto el cinturón de Lyon - y ahora este de Tarragona- todos los hallazgos de estos cinturones se concentran en el limes danubiano y la Dacia desde fines del siglo II en adelante, faltando totalmente en Britannia, el Rhin o África (Petculescu, 1991:

3 Para los cingula militaria son imprescindibles los estudios de Stefanie Hoss (2006, 2011 y 2017). 
393-394; Redžić, 2009: 158-159). Por el contrario, en los asentamientos militares del limes del Rhin y también en el sur de Britannia, abundan las placas cuadrangulares de cinturón decoradas con motivos figurados: bustos entre cornucopias, loba con los gemelos y animales, lo que permite caracterizar hábitos de vestuario diferenciados entre unas y otras legiones (Bishop y Coulston, 2006: 106-109; Hoss, 2011: 42).

El problema sin embargo es que nuestra letra tarraconense es una $\mathrm{S}$ y como tal no tendría cabida de forma estricta en un cinturón de la serie UTERE FELIX. Afortunadamente, el estudio de S. Hoss (2006) nos proporciona dos paralelos que nos permiten considerarla una variante de este tipo de cinturones: están igualmente documentadas dentro de la serie una letra "S" aislada procedente del castrum de Oberstimm / Manching, junto al Danubio al norte de Múnich (Hoss, 2006: 239 y lám. 2.4) y una segunda letra "S" unida a engarce procedente de Maria Saal (Klagenfurt,

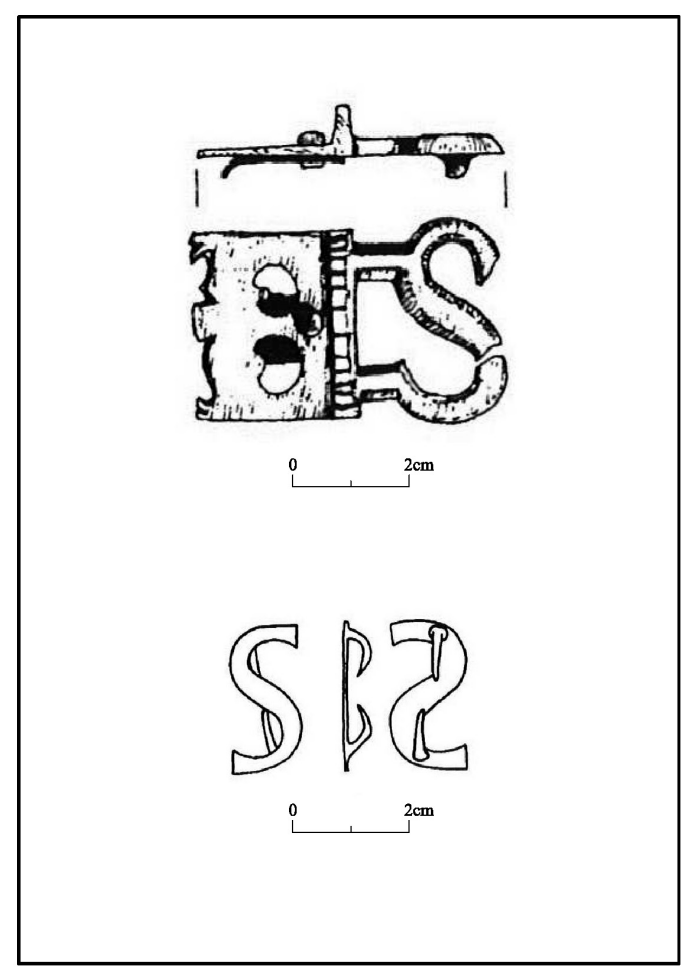

Figura 6. Letras S de cinturones militares. Arriba, unida a engarce procedente de Maria Saal (Klagenfurt, Carintia, Austria); abajo, procedente del castrum de Oberstimm (Manching, junto al Danubio al norte de Múnich) (de Hoss 2006).
Carintia, Austria) donde la letra es inicio de palabra, ya que uno de los dos arcos de la letra $\mathrm{S}$ es con claridad más grande y debería en buena lógica caligráfica ir debajo (Hoss, 2006: 240 y lám. 3.47, cat. núm. 47) (Fig. 6).

Debían existir pues variantes de estos cinturones militares incluyendo por ejemplo el nombre de su posesor en genitivo acompañando a la expresión salvífica. Esta posibilidad aparece documentada por ejemplo en dos hebillas idénticas aparecidas juntas en una tumba en cista de Dujmovača cerca de Salona, una de ellas con la inscripción incisa UTERE FELIX y la segunda FIRMICI (Bullinger, 1972: 276). En la Dacia son también frecuentes los anillos con exclamación Utere Felix que en ocasiones va unida de nuevo al nombre del propietario, por ejemplo en un anillo de Potaissa-Turda inscrito UT(ere) F(elix) VAL(erii) datado en los inicios del siglo III d. C. (Hamat, 2017: 65 pl. I.4) o en el caso de un anillo de oro facetado presente en una tumba infantil de Dierna-Orșova con inscripción (palma)-UT(ere) F(elix) C(a)ESARI-(hedera) (Hamat, 2017: 65 y pl. I.5). Las dataciones se sitúan siempre en los siglos II a IV d. C.

Por examinar otras variantes nos referiremos también a dos casos hispanos con la expresión salvífica incluyendo nominales: el asa de un vaso de oro encontrada en el área de la antigua Titulcia (Ciempozuelos, Madrid) con inscripción Utere Felix Simplici $\left(C I L \mathrm{II}^{2}, 13,6\right)$ o el famoso mosaico de la villa romana de Carranque (Toledo) con titulus dentro de cartela Ex of(f)icina Mas[-]R[--Jani / pingit Hirinius / utere felix Materne / hunc cubiculum $\left(C I L \mathrm{II}^{2}, 13,100\right)$ donde el artesano musivario y su taller deseaban al dominus Maternus el disfrute de su dormitorio personal.

Otro caso más elaborado que traemos a colación con expresión similar es la recogida en una rodela metálica procedente de Roma, hoy conservada en la Biblioteca Nacional de París. Muestra una decoración incisa superior de dos formaciones militares opuestas, con vexilla rotulados respectivamente como de la $\operatorname{Leg}$ (io) $X X$ / V(aleria) $V($ ictrix) y de la Leg(io) se/cunda / Augus(ta) y estandartes de jabalí y tritón, mientras que un aquila central se sitúa sobre el nominal Aurelius / Cervianus, probablemente un prefecto al mando de sendas vexillationes de dos legiones que intervinieron en la invasión de Britannia con Claudio. El campo inferior muestra por el contrario un ambiente cinegético con ciervo (quizás en alusión al patronímico), león, pavos y perros junto a la 
invocación Utere felix (CIL 15, 7164; Moralejo, 2014: 168).

En último lugar no podemos excluir otras posibilidades igualmente documentadas en el siglo III de letras metálicas decorando cinturones con otras expresiones en referencia a las unidades de sus poseedores. A este respecto se han señalado los casos de un cingulum con la inscripción LEG III CYR en referencia la III Legión Cirenaica (Fischer, 2012: fig. 139; cit. Hoss 2017, fig. 16), y un hallazgo funerario de la Urbs en colección privada. Se trata de un cinturón con la inscripción (hebilla)-LEONI en dativo utilizando letras de plata muy recargadas, posible regalo de Caracalla a uno de sus guardaespaldas escitas y germanos, a los que habría ascendido al grado de centuriones con el apodo de sus leones (Fischer 2012: 125; cit. Hoss 2017, fig. 7).

\section{APROXIMACIÓN AL PROPIETARIO DEL CINTURÓN TARRACONENSE}

El hallazgo en el entorno de Tarraco de uno de estos cingula ha de ser puesto en relación con otras evidencias documentadas epigráficamente de soldados procedentes del limes oriental que se trasladaron y fallecieron en Tarraco a fines del siglo II e inicios del siglo III d. C. Nos referimos por ejemplo a M. Aurelius Lucilius Poetovioni, un viejo centurión y antiguo eques singularis, la guardia montada del emperador, con 60 años de edad y cuarenta de servicio en 6 legiones diferentes, siendo la última de ellas la VII Gemina (RIT $\left.178=C I L \mathrm{II}^{2}, 14,2,1031\right)$. Su presencia en Tarraco, junto a su mujer y sus hijos (que le dedicaron su lapida funeraria) y con una edad tan avanzada tuvo que ser la de un experto instructor de jinetes apodado Poetovioni "el de Poetovio", actual Pettau en la Panonia, acuartelamiento de la legio XIII Gemina hasta época de Domiciano y luego con Trajano colonia de veteranos en la que debió nacer este centurión.

La presencia en Tarraco de este instructor de jinetes ha de ser puesta en relación con otra lápida tarraconense contemporánea datada de forma muy precisa el día 1 de marzo del año 182 por el centurión de la VII legión Tito Aurelio Décimo, un nuevo instructor de jinetes (campidoctor). El pedestal fue ofrendado a Mars Campester, el dios Marte del campus, es decir el terreno de ejercicios y parada anexo a todo campamento de la caballería, en un epígrafe ofrendado a la salud del empe- rador Cómodo y los jinetes de su guardia montada donde nuestro centurión inició su vida militar antes de pasar a la legión VII en Hispania ${ }^{4}$.

La existencia en Tarraco del officium provincial al servicio del gobernador en el que estaban destacados de forma permanente un contingente de soldados de la legión VII empleados en labores de archivo, correspondencia, policía, guardia de corps y transmisión de mensajes provocó igualmente que la ciudad fuera el lugar escogido para establecerse por muchos de estos militares una vez acabados los años de servicio (Mar y Ruiz de Arbulo, 2011; Moralejo, 2019). Los grados de estos militares puestos por orden de escalafón de mayor a menor serían los siguientes: el princeps officium o jefe del gabinete debía ser un centurión con experiencia en el officium; su ayudante, optio praetorii, era un segundo centurión al frente de todos los subordinados. Seguían dos o tres cornicularii (el nombre hacía referencia al corniculum, pequeño cuerno puesto en el casco como decoración al valor), que eran responsables de la correspondencia y el reparto de los asuntos a tratar, con grado de decuriones. Tenían como ayudantes a los adiutores officii corniculariorum, con categoría de legionarios immunes. Seguían dos o tres commentarienses, de grado inferior a los cornicularii, responsables del archivo y de los procesos verbales judiciales. En las oficinas del gobernador se debían preparar los informes relativos a toda la actividad militar de la provincia: traslados, ascensos, licencias y nuevos reclutamientos, además de redactar las sentencias judiciales y llevar al día la correspondencia.

Un grupo aparte estaba compuesto por los agentes de policía. Eran estos en primer lugar los speculatores, agentes de información, encargados de detenciones e interrogatorios. Seguían los beneficiarii que aseguraban las comunicaciones en el interior de la provincia con diferentes stationes repartidas a lo largo de la misma y en tercer lugar

${ }^{4}$ RIT $38=$ CIL II ${ }^{2}$, 14, 2, 839: Marti campestri sac(rum) / pro sal(ute) / imp(eratoris) M(arci) Aure(lii) Commodi / Aug(usti) et equit(um) sing(ularium) / T(itus) Aurel(ius) Decimus / (centurio) leg(ionis) VII g(eminae) fel(icis) / praepositus simul et / camp(idoctor) dedic(avit) K(alendis) Mart(iis) / Mamertino et Rufo co(n)s(ulibus). «Al sagrado Marte campestre, por la salud del emperador Marco Aurelio Cómodo Augusto y los equites singulares. Tito Aurelio Décimo, centurión de la legión VII Gémina y Feliz, a la vez prepósito e instructor, dedica (esta lápida) en las calendas de marzo del año de los cónsules Mamertino y Rufo». La fecha indicada corresponde al día 1 de marzo del año 182 d. C. Cf. Ruiz de Arbulo (2011). 
los frumentarii, mensajeros de élite más allá de los límites de la provincia, pero también espías y ejecutores. Todos estos officiales compartían como insignia la lanza característica de los beneficiarii. A sus órdenes actuaban una serie de soldados immunes, es decir exentos de los trabajos pesados en la vida cuartelera: quaestionarii, implicados en la actividad judicial, librarii, notarii, exceptores, tesserarius y exacti, distintos tipos de secretarios, archiveros y copistas. Las estimaciones sobre el número de integrantes de este officium a lo largo del Imperio es que no pasaría de los 100 miembros, a los que habría que añadir otros 100 stratores a modo de guardia de honor (Haensch, 1997; Rankov, 1999; Bérard, 2015; Olmo, 2018). Un contingente de 500 singulares con funciones policiales fue también habitual en las provincias que, como la Tarraconense, contaban con guarnición legionaria (Olmo, 2018: 241).

Si en el caso del cinturón de Lyon la cronología monetal sugiere su relación con la batalla del 19 de febrero del año 197 que significó la muerte de Clodio Albino, hemos de recordar igualmente que entre sus partidarios se encontraba - junto a buena parte de la nobleza hispana - el legado gobernador de la Hispania Citerior Novius Rufus, cuyo nombre aparece en la lista de los 41 senadores que Septimio Severo hizo ejecutar (SHA, Sev. 13; Alföldy 1969: 42-43: Ruiz de Arbulo 1993). El cargo de gobernador fue ocupado entonces por uno de los hombres de confianza de Septimio Severo el general T. Claudius Candidus (CIL II ${ }^{2} / 14$, 975) homenajeado en Tarraco por su ayudante el hastatus Silius Hospes con el resumen de todo su cursus honorum incluyendo la mención de que en Hispania había derrotado en tierra y mar a los rebeldes enemigos públicos ${ }^{5}$. Es evidente que la ejecución del gobernador Novius Rufus y su sus-

\footnotetext{
5 Tib(erio) Cl(audio) Candido co(n)s(uli) / XVvir(o) s(acris) f(aciundis) leg(ato) Augg(ustorum) / pr(o) pr(aetore) provinc(iae) H(ispaniae) c(iterioris) / et in ea duci terra marique / adversus rebelles hh(ostes) pp(ublicos) / item Asiae item Noricae / duci exercitus Illyrici / expeditione Asiana item Parthica / item Gallica logistae civitatis / splendidissimae Nicomedensium / item Ephesiorum leg(ato) pr(o) pr(aetore) provin(ciae) / Asiae cur(atori) civitatis Teanensium / allecto inter praetorios item / tribunicios proc(uratori) XX hered(itatium) per / Gallias Lugdunensem et Bel/gicam et utramq(ue) Germaniam / praeposito copiarum expediti/ onis Germanicae secundae / trib(uno) mil(itum) leg(ionis) II Aug(ustae) praefecto / coh(o)rtis secundae civium / Romanorum / Silius Hospes hastatus leg(ionis) X/Geminae strator eius / optimo praesidi. Cf. Alföldy 1969: 43-45.
}

titución por el general Claudio Cándido tuvo que significar un cambio total del officium provincial en Tarraco y de sus integrantes. Entre los hombres de confianza de Cándido pudo haber soldados que le acompañaron en diferentes etapas de su dilatada carrera militar a lo largo de todas las fronteras del Imperio incluyendo una campaña contra los partidarios de Víndex en el Noricum en el año 196 (Alföldy, 1969: 44).

Instalados en Tarraco con sus familias, los soldados convertidos en veteranos pudieron buscar luego una propiedad agraria en el entorno de la capital o desempeñar un oficio de acuerdo con la especialidad adquirida en los años de servicio activo. Uno de ellos, trasladado a Tarragona desde una de las legiones destacadas en el limes danubiano, debió ser sin duda el propietario de este cinturón tarraconense, al que tenían derecho no solo los militares en activo, sino también los veteranos ya licenciados. Las numerosas tumbas que han proporcionado elementos de estos cinturones prueban hasta qué punto eran bienes preciados. Se trataba, pura y simplemente, de símbolos de la milicia (Hoss, 2011).

\section{BIBLIOGRAFÍA}

Abascal, J. M. (2003): «Grafito cerámico con la fórmula utere felix en Villanueva de la Fuente», L. Benítez de Lugo (dir.), Mentesa Oretana 1998-2002. Ciudad Real, Anthropos: 243246.

Alföldy, G. (1969): Fasti Hispanienses. Wiesbaden, F. Steiner Verlag.

Bérard, F. (2015): L’armée romaine à Lyon. Roma, École Française de Rome.

Bishop, M. C. y Coulston, J. C. N. (2006): Roman Military Equipment: From the Punic Wars to the Fall of Rome. Londres, Oxbow Books.

Bullinger, H. (1972): «Utere felix. À propos de la garniture de ceinturon de Lyon». Gallia, 30-2: 276-283.

Fernández Ochoa, C.; Gil, F. y Guiral, C. (2010): «Un later pintado de la villa de Veranes (Gijón, España)», I. Bragantini (ed.), Atti del $X$ Congresso Internazionale dell'Association internationale pour la peinture murale antique (2007, Napoli). Annali di Archeologia e Storia Antica, 18/2: 735-741.

Fischer, Th. (2012): Die Armee der Caesaren. Regensburg, Verlag Friedrich Pustet. 
Galić, M. y Radman-Livaja, I. (2006): «Vtere Felix. Pojasna garnitura iz Varaždinskih Toplica». Vjesnik Arheološkog muzeja u Zagrebu (VAMZ), 39-1: 165-186.

Guillaud, L. (2019): Militaria de Lugdunum. Étude de l'armement romain et de l'équipament militaire à Lyon (Ier s. av. - IVe s. ap. J.-C.). Lyon, Editions Mergoil.

Haensch, R. (1997): Capita provinciarum. Statthaltersitze und Provinzialverwaltung in der römischen Kaiserzeit. Mainz, Verlag Philipp von Zabern.

Hamat, A. C. (2017): «UTERE FELIX inscribed rings discovered in Roman Dacia». Sargetia. Acta Musei Devensis, 8: 57-70.

Hoss, St. (2006): «UTERE FELIX und MNHM $\Omega N$ - $\mathrm{Zu}$ den Gürteln mit Buchstabenschlangen». Archäologisches Korrespondenzblatt, 36-2: 237-253.

Hoss, St. (2011): «The roman military belt», M. L. Nosch (ed.), Wearing the Cloak. Dressing the soldier in roman times. Oxford, Oxbow Books: 29-44.

Hoss, St. (2017): «Sharp dressed men: the Roman military belt as fashion item». Journal of Roman Military Equipment Studies, 18: 85-99.

Mar, R. y Ruiz de Arbulo, J. (2011): «Tarragona romana. República i Alt Imperi (anys $218 \mathrm{aC}$ $265 \mathrm{dC}) »$. Història de Tarragona, vol. 1. Lleida, Pagès: 205-538.

Moralejo Ordax, J. (2014): Ubi fuerunt. Soldados $y$ territorios en la Hispania citerior altoimperial. Entre epigrafia y arqueología. Tesis doctoral leída en la UAB. Barcelona, UAB ed. digital.

Moralejo Ordax, J. (2019): «Soldados y monumentos funerarios en Tarraco (siglos I-III d.C.). Los pedestales como elementos de prestigio en la representación sepulcral de los centuriones y principales». Epigraphica, LXXXI, 1-2: 527-552.

Olmo López, R. (2018): El centro en la periferia: las competencias de los gobernadores provinciales romanos en Hispania durante el Principado. Zürich, LIT Verlag.
Ovčarov, L. D. (1979) = Овчаров (1979): «Тракийска надгробна могила и светилище от III в. на н. е. при с. Люблен, Търговищки окръг». Археология, 3: 33-46.

Petculescu, L. (1991): "Utere felix and optime maxime con(serva) mounts from Dacia», V. A. Maxfield y M. J. Dobson (dirs.), Roman frontier studies 1989: proceedings of the 15th International congress of Roman frontier studies. Exeter, University of Exeter Press: 392-396.

Petculescu, L. (1995): «Military equipment graves in Roman Dacia», C. van Driel-Murray (dir), Roman military equipment: experiment and reality, Journal of Roman Military Equipment Studies, 6: 105-145.

Radman-Livaja, I. (ed.) (2010): Finds of the roman military equipment in Croatia. Zagreb, Arheoloski Muzej.

Rankov, B. (1999): «The governor's men: the officium consularis in provincial administration», A. Goldsworthy y I. Haynes, (eds.), The Roman Army as a community. JRA Suppl. 34, Portsmouth: 15-34.

Redžić, S. (2009): «VTERE FELIX belt sets on the territory of Viminacium». Starinar, LVIII: 155-162.

Ruiz de Arbulo, J. (1993): «Edificios públicos, poder imperial y evolución de las elites urbanas de Tarraco», Ciudad y comunidad cívica en Hispania (siglos II y III d.C.). Madrid, Casa de Velázquez-CSIC: 93-114.

Ruiz de Arbulo, J. (2011): «La dedicatoria a Mars Campester del centurión T. Aurelius Decimus y el campus de la guarnición imperial de Tarraco en el siglo II d.C. Algunas reflexiones sobre la topografía militar de la capital provincial». Cuadernos de Prehistoria y Arqueología, 37-38: 553-569.

Ulbert, G. (1974): «Straubing und Nydam. Zu römischen Langschwertern der späten Limeszeit», K. G. Kossack y G. Ulbert (eds.), Studien zur Vor-und frühgeschichtlichen Archäologie, Múnich, Verlag C. H. Beck: 197-216.

Wuilleumier, P. (1950): «Lyon. La bataille de 197». Gallia, 8: 146-148. 